\title{
ADAPTAÇÕES NO PROCESSO DE INCLUSÃO - SÍNDROME DE DOWN NA ÓTICA: CURRÍCULO, AVALIAÇÃO E MATERIAIS DIDÁTICOS
}

Suzana Lopes Salgado Ribeiro(*) Érica Andrea Cortez Monteir ${ }^{(* *)}$

$\mathrm{Na}$ contemporaneidade, a chamada Sociedade Inclusiva desestabilizou concepções e estruturas sociais, denunciando assim estruturas e preconceitos relacionados às pessoas com deficiências.

Segundo Fernandes (2011, p. 27) "até o século XVI, não havia na sociedade e sistema educacional a preocupação em oferecer atendimento especializado às pessoas consideradas diferentes".

$\mathrm{Na}$ educação são questionadas teorias e práticas que muitas vezes têm seu foco voltado ao aluno idealizado pelo sistema como um todo ainda medido por um modelo classificatório e, assim, por si excludente.

Embora se tenha muitos obstáculos a superar, faz-se pertinente e necessário ao profissional da educação, a partir do coletivo, modificar os paradigmas e ampliar os horizontes através do tema que esta pesquisa pretende refletir: A importância dos materiais adaptados no processo de inclusão de alunos com deficiência intelectual síndrome de Down na ótica do currículo e da avaliação.

Nesta perspectiva os materiais pedagógicos adaptados para os alunos com deficiência intelectual- síndrome de Down consiste em uma das formas de atender às suas necessidades inovando e melhorando o processo de ensino e aprendizagem através das adaptações.

Os materiais adaptados são recursos indispensáveis para colocar em prática, com propriedade e certeza de êxito, essa nova forma de ensino inclusivo na sala de aula para os alunos com deficiência intelectual - síndrome de Down podendo constituir uma parte diversificada do currículo e da avaliação, para apoiar ou dar suporte, bem como, complementar e suplementar o processo ensino aprendizagem.

\footnotetext{
${ }^{(*)}$ Doutora em História Social pela Universidade de São Paulo (USP). Professora do Mestrado em Desenvolvimento Humano da Universidade de Taubaté (UNITAU). Pesquisadora de Grupos de pesquisa como NEHO-USP, CESIMAPUC/SP e Educação: formação profissional, diversidade e metodologias (UNITAU). ORCID ID: <http://orcid.org/ 0000-0003-1781-3289>.

${ }^{(* *)}$ Psicóloga, Pedagoga e Psicopedagoga, Mestra em Desenvolvimento Humano pela UNITAU. ORCID ID: <https:// orcid.org/0000-0002-4351-4816>.
} 
O objetivo geral do trabalho é, por conseguinte, pretende-se, para tanto, mostrar que através dos materiais adaptados, estes favorecem as funcionalidades e potencialidades desses alunos, pois assim, construiremos uma prática reflexiva e inclusiva. Neste artigo pretende-se apresentar as, concepções, definições e classificações da deficiência intelectual - síndrome de Down, sob a ótica das práticas pedagógicas, dos currículos e das avaliações para o processo de inclusão, sugeridos no contexto do presente trabalho.

As políticas sociais dos governos estão cada vez vinculadas às ampliações da cidadania, na base deste processo estão os direitos fundamentais da pessoa humana, dentre esses direitos, destacadamente, vêm o direito a educação.

$\mathrm{O}$ art. 205 da Constituição Federal (CF/1988) dispõe, in verbis: Art. 205. A educação, direito de todos e dever do Estado e da família, será promovida e incentivada com a colaboração da sociedade, visando ao pleno desenvolvimento da pessoa, seu preparo para o exercício da cidadania e sua qualificação para o trabalho.

Entende-se desta forma que as pessoas com deficiência intelectual - síndrome de Down gozam do mesmo direito dos demais cidadãos. Assim a Educação Inclusiva é também caracterizada por um conjunto de recursos e atividades específicas e organizadas as quais tem função de apoiar, orientar o aluno com deficiência intelectual no ensino regular.

\section{DEFICIÊNCIA INTELECTUAL - SÍNDROME DE DOWN: DEFINIÇÕES E CLASSIFICAÇÕES}

A compreensão sobre as patologias do desenvolvimento humano foi consolidada a partir dos preceitos da ciência moderna, segundo Pan (2010) através de seus métodos de observação, classificação, e descrição, que são base do modelo de diagnóstico clínico, os quais levaram à crença na relação direta entre sintomatologia clínica e lesões anatômicas e que adquiriu o termo de moléstia física, pelo qual, várias anomalias são agrupadas em um só quadro, e diferenciadas apenas em níveis, de acordo com os sintomas comportamentais, porém as etiologias orgânicas diversas e as anomalias estavam sempre relacionadas à déficits irreversíveis da atividade mental superior.

Tal compreensão da deficiência, enquanto moléstia física foi consolidada em Londres, no século XVII, conforme observava Pessoti, com a publicação em 1664 do Cerebri Anatome, de Thomas Willis (1625-1675), que se propôs em entender a idiotia e outras deficiências como produto de estruturas ou eventos neurais, a partir das descrições anatômicas e conceitos fisiológicos, relacionando-os a lesões no sistema nervoso central (PAN, 2010, p. 39). 
Partindo desta compreensão em relação à deficiência intelectual, somente na idade moderna foi que se deu um novo sentido a este conceito, porém ainda persiste o mito sobre a irrecuperabilidade em relação à deficiência.

A deficiência intelectual passou a ser considerada como um estágio de carência de ideias e operações intelectuais ao vivido pelos recém-nascidos, e que desta teoria iria frutificar a concepção ambientalista, em que a influência do meio tem o papel decisivo no desenvolvimento humano (PAN, 2010).

Portanto, no ambientalismo nasce a ideia de recuperabilidade da deficiência intelectual, até então entendidos como irrecuperáveis, originando a crença da educabilidade da pessoa com deficiência intelectual, atribuindo exclusivamente ao ambiente e privilegiando as experiências que se tem do mesmo, como fonte para novas aprendizagens.

Para Pan (2010), no século XX a psicologia ganhou destaque com Alfred Binet (18571911), que possibilitou a construção do termo deficiente mental, entendendo a mesma pela luz da psicometria, bem como a classificação QI, em níveis, Educabilidade-leve, (educável), moderada (treinável), severa e profunda.

A prática psicológica substituiu os rótulos qualitativos idiota, cretino, imbecil, por critérios quantitativos, o que promoveu o avanço e a inserção das práticas pedagógicas para os deficientes intelectuais, baseados em avaliação psicológica, porém eles classificam as pessoas de forma padronizada, o que muitas vezes gera rótulos e discriminação.

Segundo o MEC (2005) desde o ano de 1983, alguns importantes acréscimos foram feitos em relação à definição da AAMR. A deficiência mental passou a ser interpretada como um estado de funcionamento, para uma expressão da interação entre a pessoa com limitações no funcionamento intelectual e seu contexto.

De acordo com Pan (2010, p. 64-65),

Outros sistemas mundiais de classificação um deles é: Diagnostic and Statistical Manual of Mental Disorders - Fourth Edition - DSM-IV (Manual Diagnóstico e Estatístico de Transtornos Mentais - Quarta Edição Revisada), da Associação NorteAmericana de Psiquiatria. Outro sistema é o da Organização Mundial de Saúde OMS, a Classificação Internacional de Doenças - CID-10, atualmente em sua décima revisão. O DSM-IV caracteriza os transtornos mentais como síndromes ou padrões comportamentais ou psicológicos com importância clínica, que ocorrem num indivíduo e adotam a classificação de retardo mental. 
Acrescenta a categoria retardo mental de gravidade inespecificada, aplicando-a quando as condições deficitárias da pessoa não permitem mensuração da inteligência.

A CID-10 apresenta uma natureza descritiva por diagnóstico, com os principais aspectos clínicos e outros associados, mesmo que menos relevantes, também admite mensuração de Q.I. como definidora de deficiência e, com base nesse índice, aplica seu (CID-10, 1993).

Existe ainda outro sistema que pertence à "família" das classificações internacionais desenvolvida pela Organização Mundial da Saúde (OMS): A Classificação Internacional de Funcionalidade, Incapacidade e Saúde, conhecida como CIF, que também relaciona os fatores ambientais que interagem com todos estes construtos. Neste sentido, a classificação permite ao utilizador registrar perfis úteis da funcionalidade, incapacidade e saúde dos indivíduos em vários domínios (CIF, 2003).

Esse sistema de classificação merece a atenção dos profissionais por oferecer um referencial teórico importante para o entendimento da deficiência intelectual. Sendo assim, o retardo mental é um dos mais antigos métodos de nomenclatura utilizada para identificar todas as pessoas com deficiência intelectual, isso se faz presente tanto no CID-10 quanto no DSM-IV, porém a CIF considera a funcionalidade e a incapacidade dos indivíduos avaliados dentro de uma perspectiva positiva, pois, considera independentemente das funções cognitivas e do corpo que os indivíduos apresentam, eles podem sim, participar ativamente da sociedade, substituindo o enfoque negativo e às vezes preconceituoso sobre o que é deficiência intelectual.

O termo deficiência intelectual é usado atualmente para definir ao que antigamente era chamado por deficiência mental. A primeira descrição da deficiência intelectual feita pelo médico inglês Jonh Longdon Dow foi relacionada à síndrome de Down, de acordo com Russo e Degen (2012) ele descreveu alguns sinais físicos em grupo de pessoas, e considerou que estas pessoas eram amistosas amigáveis, amáveis, mas improdutivas e incapazes para viver socialmente, por não corresponderem seus comportamentos com o esperado da época. A síndrome de Down é conhecida como a trissomia do 21 , e a deficiência intelectual tem sido considerada uma das características mais constantes da síndrome (HONORA; FRIZANCO, 2008).

Segundo Schwartzman (1999), há um inevitável atraso em todas as áreas do desenvolvimento e um estado permanente de deficiência intelectual na Sindrome de Down. Porém, segundo o mesmo autor, não há um padrão previsível de desenvolvimento em todas as crianças afetadas, uma vez que o desenvolvimento da inteligência não depende exclusivamente da alteração 
cromossômica, mas também do restante do potencial genético, bem como das importantes influências do meio.

Outros estudos sobre a inteligência humana merecem ser contemplados em uma nova perspectiva pedagógica para superar o conceito unitário e determinista do Q.I. (Quociente de Inteligência).

Diferentes fundamentações teóricas vêm deslocando a análise da deficiência intelectual para o campo das disfunções nos processos cognitivos ou na atividade mental superior.

Entre as teorias, destaca-se a epistemologia genética, de Piaget, que deixou pistas significativas para pensarmos a inteligência humana sob uma nova perspectiva. Segundo Pan (2010) a teoria piagetiana aponta para a troca do organismo com o meio através de uma ação física ou mental, sendo, portanto, a inteligência um processo dinâmico, de ação executada entre objeto e a pessoa, desta maneira as estruturas da inteligência vão se construindo.

Os estímulos do meio são fundamentais para o desenvolvimento da inteligência, quanto mais estímulos, mais se desenvolve a inteligência humana, o que vale afirmar que a inteligência humana pode ser exercitada.

Outro autor também deu grande contribuição sobre o desenvolvimento da inteligência, que atingiu uma dimensão educacional inclusiva foi Vygotsky.

Segundo Fernandes (2011) Vygotsky desenvolveu sua teoria baseado no conceito de compensação que sistematiza o princípio da determinação social e caráter. Isto mostra que o desenvolvimento das funções superiores como linguagem, o pensamento abstrato, o raciocínio lógico, memória atenção e outros processos mentais, acontece sobre as bases das funções naturais, que segundo ele é no contexto das relações interpessoais desenvolvidas em seu grupo social e cultural. A consciência é social e historicamente determinada, sendo suas funções constitutivas dos modos de pensamento e da inteligência (memória, atenção, solução de problemas e simbolização etc., a educação deve ocupar-se do que pode ser medido na criança, de modo que a zona de desenvolvimento proximal tornar-se, amanhã a zona real de ação cognitiva) (PAN, 2010).

Neste sentido a inteligência não pode ser baseada no déficit, mas nas diferentes formas da criança lidar com a aprendizagem por meio da mediação, é na relação com o outro, que a inteligência se desenvolve.

De acordo com Fernandes (2011), Vygotsky, assume que a deficiência não deve ser explicada com base em componentes biológicos, mas sim sociais, e que somente uma educação 
centrada na compensação social dos problemas orgânicos poderia contribuir para superação das dificuldades. Para ele um sistema de ensino deveria ser planificado e sistematizado, em detrimento de práticas espontaneístas, levaria as crianças com deficiência a superar suas dificuldades, potencializando o seu desenvolvimento de estruturas e sistemas psicológicos complexos por meios de mecanismo de correção e compensação.

Segundo Vygotsky (1998), as crianças deficientes devem usar seus sentidos sadios para compreenderem o mundo, isto é, as crianças devem desenvolver seus sentidos normais para compensarem seus sentidos perdidos (visão, audição, etc.), outro sentido seria privilegiado para compensar o que estava defeituoso.

Considerando as influências e as transformações que aconteceram, enquanto paradigma merece hoje mudanças de concepções frente à deficiência intelectual, do mesmo modo é preciso que o professor e as pessoas reflitam sobre a ideia da sociedade inclusiva tendo como horizonte a participação de todas as pessoas com deficiência ou não, todas as oportunidades independentes, de suas peculiaridades individuais.

\section{A FLEXIBILIDADE ADAPTAÇOES DO CURRÍCULO O PAPEL DO PROFESSOR}

Segundo o MEC (2005) a ideia de flexibilidade curricular é considerada fundamental para o processo de inclusão educativa e deve ser pensada a partir do grupo de alunos e a diversidade que o compõe e não para alguns alunos isoladamente e a flexibilidade curricular pode ser viabilizada a partir de adequações curriculares e adaptações curriculares.

Sendo assim, as deficiências não impedem a participação e contribuição desses alunos na sociedade. Sabe-se que eles podem ser parte ativa da sociedade e agente participativo em seu próprio desenvolvimento, desde que lhe sejam dadas condições para aprender.

Ainda, segundo o MEC (2005) com relação à proposta pedagógica, cabe apontar a importância das flexibilizações curriculares, para que possam ser facilitadoras, e não dificultadoras. Sendo assim, as adequações curriculares necessitam ser pensadas a partir do contexto grupal em que se insere determinado aluno.

Faz-se necessário que o professor norteie suas ações voltadas para trabalhar com a perspectiva inclusiva na escola com esses alunos. Tais questões da resolução apontam desafios a serem enfrentados e a necessidade que essa temática seja discutida por todos envolvidos na escola e contemplada no projeto político pedagógico e no currículo como uma questão inerente à própria concepção de educação e aprendizagem. 
As adaptações curriculares devem ser pensadas a partir de cada situação particular e não como propostas universais, válidas para qualquer contexto escolar. As adequações feitas por um determinado professor para um grupo específico de alunos só são válidas para esse grupo e para esse momento (MEC, 2005).

O currículo não deve ser concebido de forma que o aluno se adapte aos moldes que ele oferece, com rigidez, sem possibilidades de diálogo, mas como um campo aberto diversidade, que seja organizado de forma com os recursos necessários para abordar os diferentes estilos de aprendizagem no sentido de que cada aluno poderia aprender coisas diferentes de diferentes maneiras, de forma dinâmica e criativa.

Para que isso aconteça é importante que o currículo da escola seja modificado, construído continuamente para estes alunos para reduzir incertezas, contradições e esforços inúteis.

As medidas apresentadas pelo constituem adequações de acesso ao currículo: criar condições físicas, ambientais e materiais para o aluno na sua unidade escolar de atendimento; propiciar os melhores níveis de comunicação e interação com as pessoas com as quais convive na comunidade escolar; favorecer a participação nas atividades escolares; propiciar o mobiliário específico necessário; fornecer ou atuar para a aquisição dos equipamentos e recursos materiais específicos necessários; adaptar materiais de uso comum em sala de aula; adotar sistemas de comunicação alternativos para os alunos impedidos de comunicação oral (no processo de aprendizagem e na avaliação) (MEC, 2005, p. 71).

Com isso, o currículo deixará de lado o modelo tradicional, procurando os aspectos flexíveis que atendam a diversidade, com esta flexibilidade será garantida a aprendizagem e o ensino terá mais coerência nos conteúdos escolares.

Isto implica em atender ao aluno com deficiência intelectual, - síndrome de Down através de intervenções educativas em um contexto singular e concreto, e o aluno com suas características específicas.

O sistema educacional tem que começar urgentemente promover um ensino para todos sem exclusões, deixar de lado o modelo tradicional, para melhora atender as necessidades de aprendizagem dos alunos. Neste sentido o currículo adaptado é fundamental para garantir a aprendizagem e facilitar as atividades em sala de aula.

De acordo com Luck (2009), existem vários princípios que norteiam a prática do professor, um destes princípios é de que a aprendizagem é um processo dinâmico, contínuo, sistemático e 
integrado, que tem todo o currículo escolar sendo assim o papel do professor deve permear todas as atividades com as demais áreas do currículo escolar e o modo de ser e fazer da escola.

Portanto, o currículo adaptado garantirá aos alunos uma educação de qualidade, estabelecendo metas até chegar na realidade concreta do aluno de forma individual, perante as habilidades, delimitará os objetivos e os conteúdos, as estratégias as intervenções necessárias para o desenvolvimento do aluno.

Almeida e Soares (2010) lecionam que a função do professor em relação a esses alunos é de garantir a aprendizagem dos conhecimentos socialmente necessários, promover uma construção de uma sociedade mais justa, levando em conta que os conhecimentos metodológicos são o caminho desde que as práticas pedagógicas sejam escolhidas de formas adequadas de atender às necessidades desses alunos para apropriação dos conteúdos.

As adaptações curriculares revelam possibilidades para o professor atuar frente às dificuldades destes alunos, a fim de tornar o currículo apropriado ao aluno, sendo este dinâmico, alterável, passível de mudanças, e que possa ser ampliado de acordo com as reais necessidades do aluno. $\mathrm{O}$ professor que ensina a turma toda não tem o falar, o ditar e o copiar dos recursos didáticos pedagógicos básicos. Ele não é um palestrante, mas é aquele que "partilha" com seus alunos a construção da autoria dos conhecimentos produzidos em aula, onde todos interagem e constroem significativamente os conceitos, valores e atitudes. (MANTOAN, 2003, p. 76-77).

Portanto, os alunos com deficiência intelectual e síndrome de Down precisa de um currículo adequado, elaborado de acordo com suas necessidades um currículo que compreenda a diferença: A de ser flexível e a de ser aberto. Flexível quando delimita as necessidades educativas, procura as necessidades educativas no processo interativo do aluno com sua situação de aprendizagem dentro processo de ensino e aprendizagem deverão ser avaliadas pelo próprio professor as necessidades educativas, em trabalho coordenado com outros profissionais da educação (professores de apoio, equipes interdisciplinares, etc.), detectarão as necessidades do aluno, avaliando-o de acordo com a proposta curricular para todos os alunos, de modo a determinar se o mesmo precisa de adaptações curriculares, analisar a situação de aprendizagem e aluno, avaliar para saber quais as necessidades educativas do aluno.

Sendo assim, o aluno com deficiência intelectual - síndrome de Down se beneficiara do currículo aberto, terá possibilidades de desenvolvimento e aprendizagem, mas para que isso aconteça deve-se levar em conta que o aluno será avaliado fundamentalmente na situação de sala de aula e também a sua situação de aprendizagem. 
A resposta educativa proporcionada ao aluno é o programa geral para todos os alunos, com adaptações mais ou menos significativas conforme suas necessidades, a adaptação curricular requer ampla coordenação e colaboração de todos os profissionais, as adaptações curriculares planejam o tipo de ajuda com base na proposta inicial para todos os alunos (ROYO; URQUIZAR, 2012).

Por isso, é que o currículo não deve ser concebido de maneira a ser o aluno que se enquadre aos moldes que a escola oferece, mas como um campo aberto às diferenças individuais e que a diversidade não é no sentido de que cada aluno poderia aprender conteúdos diferentes, mas sim aprender conteúdos de diferentes maneiras, pois cada um tem um ritmo próprio de aprender, formas cognitivas diferentes de interpretar, diferentes estilos, capacidades interesses e motivações, e ter claro em mente que os processos de aprendizagem não são uniformes.

Não se adapta um currículo, tendo como desculpa a incapacidade de alguns, mas a capacidade diversificada de cada um dos alunos, para enfrentar as exigências da escola, capacidade essa que não é medida por testes, ou definida por objetivos específicos para este ou aquele, individualmente, mas apreciada a posteriori, pelo produto da aprendizagem de cada um. Porque é o aluno que adapta os esquemas de ação e suas estruturas de conhecimento às tarefas de aprendizagem. E essas adaptações é que precisam ser aceitas pelo professor, como respostas ativas e particulares de cada aluno, às solicitações gerais do meio escolar. (MANTOAN, 1998, p. 120).

Para efetivar tal acontecimento, ao planejar, o professor precisa estabelecer objetivos, criar oportunidades para todos os alunos aprenderem com sucesso, incluídos todos em suas diferenças.

Segundo Cucolicchio (2012) o princípio básico da inclusão escolar, consiste em que todas as escolas devem reconhecer as diversas necessidades dos alunos e a elas respondam, assegurandolhes uma educação de qualidade promovendo a aprendizagem por meio do currículo apropriado, fazendo modificações organizacionais, estratégias de ensino e uso de recursos adaptados entre outros.

Portanto, as adaptações curriculares devem ser a busca do professor, para melhor compreender as reais necessidades do aluno, aperfeiçoando-as, modificando-as quando necessário, a fim de possibilitar o desenvolvimento integral do aluno no processo de ensino e aprendizagem.

\section{ADAPTAÇÕES METODOLÓGICAS, DIDÁTICAS E AVALIATIVAS}

A situação da educação escolar inclusiva não se limita ao aspecto didático-pedagógico. A inclusão escolar também é sócio afetiva. O educando deve sentir-se acolhido e perceber que a 
diversidade não se constitui um obstáculo e sim um estímulo para a formação de consciência de todos os envolvidos no processo sócio educacional e afetivo. (BRASIL SECRETARIA DE EDUCAÇÃO ESPECIAL, 2002).

A Lei de Diretrizes Bases da Educação Nacional (9.394/96) define metas e pontuações na área da Educação Especial, em seu artigo 59 no qual defende a individualidade, a integridade da pessoa com necessidades educativas especiais por referir-se a pessoa como um ser único quando prevê que os sistemas de ensino assegurarão aos educandos com necessidades especiais currículos, métodos e técnicas, recursos educativos e organizações específicas para atender suas individualidades.

Segundo Luck (2009), em decorrência da escola ser um processo cooperativo e integrado em que todos os educadores, em especial o professor, assumem papel ativo e relevante na aprendizagem.

Cabe então dizer que o trabalho pedagógico integrado com o aluno é fundamental para o desenvolvimento, pois ele ajudará a criar um ambiente favorável e equilibrado e propício ao desenvolvimento de aprendizagem e respeitando o aluno na sua individualidade.

Segundo Pimenta (1995), o professor tem que adotar várias ações que podem ser desenvolvidas por ele no que concerne à aprendizagem desses alunos com deficiência intelectual síndrome de Down ele poderá identificar as dificuldades de aprendizagem bem como buscar, formas de ajudar os alunos a superarem as dificuldades. Criando estratégias de investigação da realidade do aluno e assessorando o professor na relação teoria, prática e realidade e avaliando o aluno dentro de uma dinâmica reconstrutiva.

A função do professor é a de contribuir para a melhoria do ensino e das condições de aprendizagem. Sendo assim ele deverá promover para os alunos com deficiência intelectual possibilidades de aprendizagem significativa, para isto deverá orientar os professores qual a melhor forma de avaliar este aluno, primeiro identificando o que o aluno já sabe propor atividades de acordo com o aluno e verificar quais habilidades precisam ser conquistadas e desenvolvidas.

Para Almeida e Soares (2010), cabe ao professor o acompanhamento sistemático da aprendizagem do aluno observando os resultados obtidos na avaliação e a sua integração na sala de aula como um todo, e a partir dessas observações fazer as adaptações necessárias, os encaminhamentos metodológicos, de forma abranger o desenvolvimento da aquisição do conhecimento desse aluno. 
Seguindo essa prática pedagógica, o professor, dará um passo fundamental de forma dinâmica, em garantir ao aluno com deficiência intelectual - síndrome de Down, a igualdade de oportunidades sociais e educacionais, elevando ao máximo seu potencial intraindividual único.

Royo e Urquizar (2012), consideram a necessidade de garantir a avaliação inicial ao começar cada processo e adequá-la ao contexto dos alunos, selecionar diversos instrumentos de avaliação, elaborar atividades em sala que envolvam a avaliação, introduzir atividades de auto avaliação.

Os planejamentos curriculares à luz dos princípios do desenvolvimento e bases científicas e da otimização dos recursos humanos e didáticos do ensino, surtem grandes resultados positivos educacionais.

O professor neste contexto tem o papel de ajudar os alunos com deficiência intelectual síndrome de Down, elaborar atividades que atendam a esta demanda, ler vários assuntos sobre a questão da adaptação curricular, a avaliação, os instrumentos adequados, aprofundando em termos teóricos e práticos nas limitações que estes alunos apresentarem e elaboração dos materiais adaptados. Avaliar é mais do que classificar o aluno, é sim promover a diferença, e não a padronização, é auxiliar na aprendizagem significativa.

Neste sentido a avaliação deve ser feita pensando em cada aluno, lançando um olhar diferenciado para cada um deles, auxiliando e intervindo no seu processo de aprendizagem.

Essa é a intenção do avaliador: conhecer, compreender, acolher os alunos em suas diferenças e estratégias próprias de aprendizagem para planejar e ajustar as ações pedagógicas favorecedoras a cada um a cada grupo como um todo (HOFFMANN, 1996, p. 14).

A avaliação até aqui é entendida como inclusiva, pois respeita as pessoas nas suas peculiaridades individuais, não restringindo aos fatos isolados, e que contribui para o desenvolvimento das pessoas com deficiência ou não, e oferecer direitos iguais a todos, compreendendo cada um na sua diferença e ajusta as práticas pedagógicas, entende que o outro tem em si uma essência diferente.

Segundo Teixeira e Nunes (2010), o oferecimento de recursos diversos e específicos para a necessidade de cada aluno é que vai oferecer na diferença das opções a igualdade de vencer na vida, constituindo uma educação para a diversidade, rompendo limites, barreiras, preconceitos e expectativas, rompendo com o modelo padronizador em benefício de um modelo, diversificado, atualizado, flexível. 
Existem alguns princípios que sustentam os instrumentos de uma avaliação inclusiva dentre eles destaca-se: A diversidade (valorizar os progressos e os resultados alcançados), o professor deve trabalhar com afetividade e a valorização da autoestima do aluno, respeitando as diferenças, identificando e incentivando os progressos alcançados, a coerência, orientação e o apoio, a avaliação deve ser um processo coerente com o que se ensina e com que se espera que o aluno aprenda, tendo o professor princípios éticos com o que se fala e o que se faz, a avaliação deve ser significativa e ter sentido para a vida e ser contextualizada e operativa, sendo assim cabe ao professor orientar o aluno de modo que ele se sinta confiante e familiarizado ao realizar as avaliações, pois dessa forma ele saberá que tipo de desafio ele terá pela frente e o que cada prova pode esperar dele. (TEIXEIRA; NUNES, 2010).

Esta orientação deve apoiar o processo de ensino e aprendizagem. Destaca-se também a prevenção da segregação (rótulos) e que toda avaliação inclusiva deve prevenir qualquer ato de ou forma de manifestação de exclusão, evitando com isso, a segregação, preferências e rotulações.

O aluno deve e tem que ser visto como pessoa que ele é e não ser rotulado por meio de sua patologia, sua deficiência física ou como aquele que não sabe nada.

A avaliação deve ser sistematizada de forma organizada em sua proposta curricular e pedagógica para que possa alcançar as práticas inclusivas da avaliação, já que tem em si objetivos específicos, organização de ideias e clareza de fatos.

O registro é uma prática importante para o acompanhamento do processo de ensino e aprendizagem, nele irá conter todo o mapeamento da aprendizagem do aluno, bem como os saberes que este já construiu e que pode vir a construir, permitindo ao professor ajustar e planejar e garantir atividades diferenciadas para que o aluno aprenda.

Existem outras formas de se organizar o currículo e as avaliações, de equivalente importância no processo educativo, mas aqui foram comentados os que mais aguçam nossa criticidade e reflexão.

Segundo Didone (2006, p. 6):

As atividades e estratégias que devem ser utilizadas com os alunos com deficiência intelectual diz a respeito da coordenação motora, que pode ser mais lenta em crianças que têm deficiência intelectual. Uma das maneiras de estimular o aluno a dominar seus movimentos é fazê-lo escrever o nome em folhas de papel de diferentes tamanhos. Assim, ele também visualiza a necessidade de aumentar ou diminuir a letra de acordo 
com o espaço, também é muito comum uma criança com deficiência mental ter problemas de oralidade.

A atividade deve sempre ser feita com a turma toda, também é necessário diversificar os meios de acesso ao conteúdo na sala de aula. Crianças com deficiência mental (e sem deficiência também) também se identificam com material concreto principalmente de Matemática, com músicas, passeios, desenhos, vídeos ou debates.

Devem ser oferecidas situações, envolvendo ações em que o próprio aluno teve participação ativa na sua execução e/ou façam parte da experiência de vida dele.

Sendo assim é necessário antes de avaliar definir o que o aluno precisa, para podermos ajudá-los em suas necessidades específicas através das adaptações, para configurar uma intervenção e uma avaliação adequada.

O processo de avaliação de desempenho do aluno tem como intuito reconhecer as dificuldades específicas, no contexto da aprendizagem, sem esquecer que de modo algum que a avaliação de desempenho e as intervenções feitas constituem um único processo.

As modificações e acomodações são necessárias e específicas para cada aluno que apresenta deficiência, e devem ser elaboradas pelo professor, pelo coordenador e administrador escolar, pois não basta incluir o aluno no ensino regular para apenas estar em sala de aula, é preciso que ele possa participar ativamente da aula.

\section{METODOLOGIA}

Para o desenvolvimento deste artigo foi realizado um estudo bibliográfico e documental.

Para tanto, selecionamos os trabalhos por meio de um levantamento e de pesquisa bibliográfica que, segundo Gil (1999), é constituída de livros e artigos científicos.

Além da pesquisa bibliográfica foi feita uma pesquisa documental que percorreu fontes variadas de documentos oficiais como legislação, que foram consultados online e devidamente citados nas referências, Da legislação foram selecionados para a presente pesquisa alguns artigos da Lei de Diretrizes Bases da Educação Nacional (Lei 9.394/96), e da Constituição Federal de 1988 e documentos do MEC.

\section{RESULTADOS}

Este artigo mostrou a importância das adaptações para o currículo e a avaliação possibilitando ao professor repensar sobre a educação inclusiva na sala de aula, afirmando que as adaptações são necessárias para o desenvolvimento do aluno com deficiência intelectual. Assim, as 
adaptações na sala de aula, a do currículo e da avaliação são essenciais para promoção do desenvolvimento.

Quanto aos sistemas de classificação científicos mostrados nesse estudo bibliográfico, tem como objetivo mostrar como é feito o diagnóstico da deficiência intelectual foram: a CID -10 (1993) que é um sistema muito usado no mundo todo como forma de listar estatisticamente doenças e condições clínicas, além de rastrear a morbidade e a mortalidade, já a CIF (2003) é de grande utilidade para o entendimento da deficiência mental englobando funções e estruturas do corpo, atividades, participação, condições de saúde e fatores pessoais e ambientais, todos interligados entre si, destaca-se nesses sistemas, também o manual DSM-IV (2002), extremamente utilizado no meio clínico e no mundo todo.

A inteligência não se define, e sim se constrói, não sendo fixa e constante durante toda a vida. A pessoa com SD é muito mais que sua carga genética, é um organismo que funciona como um todo, e a genética é só uma possibilidade. Esse modo de funcionar como um todo, pode compensar inclusive sua carga genética, mediante processos de desenvolvimento, sempre e quando melhoram os escolares)

Em reforço a essas considerações, vale frisar que esta pesquisa não esgota o assunto e pode se desdobrar em pesquisas mais extensas com outras fontes e referenciais teóricos. Todavia, mesmo com limitações este trabalho, tem a virtude de refletir e apontar caminhos para futuros pesquisadores, além servir de referencial teórico inicial.

\section{CONCLUSÃO}

Neste artigo, foram estabelecidas quais as vantagens de se adotar o material adaptado para os alunos com deficiência intelectual - síndrome de Down, segundo enquanto proposta de intervenção inovadora no sistema educacional, por meio do currículo e das avaliações

Por pertencerem ao universo de ensino escolar e por extensão, aos alunos com deficiência intelectual - síndrome de Down em seu sentido mais amplo, os materiais adaptados e as adaptações no currículo e nas avaliações, perpassam pela reflexão visionária, a fim de reverem os conceitos de educação e qualidade, independente das diferenças individuais das pessoas e que ao longo do tempo, os materiais adaptados, ganham atualizações. Essas atualizações são necessárias para facilitar a realização de atividades para quem possui alguma limitação.

Confirma-se, pois, diante dos estudos realizados acerca da importância, das adaptações do currículo e das avaliações para o bom desempenho do aluno com deficiência intelectual - síndrome 
de Down no ensino regular. Os materiais adaptados para o aluno é um recurso riquíssimo para se trabalhar, juntamente com o currículo e a avaliação, ajudam a responder às diversas dificuldades, sempre respeitando os diferentes estilos e ritmos de aprendizagem.

Além do mais, é fundamental que a educação inclusiva seja centrada no ser humano e não em sua deficiência ou patologia, e o desenvolvimento humano está intrinsecamente relacionado ao contexto sociocultural em que se insere, portanto é impossível considerá-lo um processo previsível e universal, por meio de classificações sobre a inteligência.

Portanto, é importante que o professor tenha como indispensável em sua prática um currículo que transcenda as concepções dos déficits, para tornar a prática pedagógica rica em experiências educativas, transformando as necessidades dos alunos com deficiência intelectual síndrome de Down no movimento de aprender, de construir, dando-lhes autonomia, e os recursos necessários.

É pertinente também que o professor avalie a si mesmo e os recursos que possui, pois nem sempre que se pensa que este ou aquele material de ensino é um recurso pedagógico. Às vezes uma lousa pode ser um recurso para o professor, mas pode não ser um potenciador pedagógico para o aluno com deficiência intelectual - síndrome de Down.

Os recursos utilizados pelo professor precisam estar vinculados às possibilidades do aprendente, através de uma avaliação das necessidades destes alunos e de suas habilidades. 


\section{REFERÊNCIAS}

ALMEIDA, Claudia Mara e SOARES, Kátia Cristina Dambiski. Pedagogo escolar: as funções supervisora e orientadora. Curitiba: IBPEX, 2010.

BRASIL. Constituição (1988). Constituição da República Federativa do Brasil. Diário Oficial da União. Brasília: Congresso Nacional, 05 out. 1988. Anexo

Lei 9.394, de 20 de dezembro de 1996. Estabelece as diretrizes e bases da educação nacional. Diário Oficial da União. Brasília: Poder Legislativo, 23 dez. 1996, sec. I, n. 248, p. 27.833.. Disponível em: <http://www.planalto. gov.br/ ccivil 03/ Leis/ L9394.htm>. Acesso em: 15 jun. 2018.

Ministério da Educação. Documento subsidiário à política de inclusão. Brasília: MEC 2005.

BRASIL. Plano nacional de educação. Brasília, 2001b.

Secretaria de Educação Especial. Portal de ajudas técnicas para educação: equipamento e material pedagógico para educação, capacitação e recreação da pessoa com deficiência física: recursos pedagógicos adaptados/ Secretaria de Educação Especial - Brasília: MEC: SEESP, 2002, fascículo 1.

CARNEIRO, Moaci Alves. O acesso de alunos com deficiência às escolas e classes comuns. Petrópolis: Vozes, 2008.

CID-10 - Classificação de Transtornos mentais e de Comportamento: Descrições clínicas e diretrizes diagnósticas Coord. Organiz. Mund. da Saúde; trad. Dorgival Caetano. Porto Alegre: Artmed, 1993.

CIF - Classificação Internacional de Funcionalidade, Incapacidade e Saúde: Classificação detalhada e com definições - Coord. Organiz. Mund. da Saúde; trad. Cássia Maria Buchalo. São Paulo: EDUSP, 2003.

CUCOLICCHIO, Simone. Inclusão Escolar. Síndromes: Revista Multidisciplinar do Desenvolvimento Humano. São Paulo, ano 2, n. 4, p. 27-28, ago. 2012.

DIDONÊ, Débora. Inclusão. Revista Nova escola: São Paulo. Edição Especial n 11, Outubro de 2006.

DSM - IV - Manual diagnóstico e estatístico de transtornos mentais, trad. Claudia Dornelles, 4. ed. Rev. Porto Alegre: Artes Médicas, 2002.

FERNANDES, Sueli. Fundamentos para educação especial. Curitiba: IBPEX, 2011.

GIL, A. C. Métodos e técnicas de pesquisa social. São Paulo: Atlas, 1999.

GRINSPUN, Mírian P. S. Zippin. A prática dos orientadores educacionais. São Paulo: Cortez, 2008.

HOFFMANN, Jussara. Avaliação mediadora: Uma prática em construção da pré-escola à universidade. Porto Alegre: Mediação, 1996.

HONORA, Marcia e FRIZANCO, Mary. Esclarecendo as deficiências: Aspectos teóricos e Práticos para contribuir com uma Prática Inclusiva. São Paulo: Ciranda Cultural, 2008.

LUCK, Heloisa. Planejamento em orientação educacional. Petrópolis: Vozes, 2009.

MANNONI, M. A criança retardada e a mãe. São Paulo: Martins Fontes, 1991. p. 42.

MANTOAN, Maria Tereza Eglér. Inclusão escolar: o que é? por quê? como fazer? São Paulo: Moderna, 2003.

MENDES, Enicéia Gonçalves, Breve histórico da educação especial no Brasil, Revista Educación y Pedagogía, Medellín, vol. 22, núm. 57, p. 93-109, maio-ago. 2010.

PAN, Mirian. O direito a diferença: Uma reflexão sobre deficiência intelectual e educação inclusiva. Curitiba: IBPEX, 2010.

PIMENTA, Selma Garrido. O pedagogo na escola pública. 3. ed. São Paulo: Loyola, 1995.

ROYO, Maria Angele Lou e URQUIZAR, Natividdad Lopes. Bases psicopedagógicas da educação especial. Petrópolis: Vozes, 2012.

RUSSO, Alessandra Freitas e DEGEN, Christine Luise. Educação Especial: Conceitos e Reflexões. Síndromes: Revista multidisciplinar do desenvolvimento humano, São Paulo: ano 2, n. 4, p. 21-23,ago. 2012.

SCHWARTZMAN, J. S. (Ed.). Síndrome de Down. São Paulo: Memnon.1999.

SILVA. Nara Liana Pereira. DESSEN Maria Auxiliadora. Síndrome de Down: etiologia, caracterização e impacto na família Universidade de Brasília. 2002. 
SMITH, Corinne; STRICK, Lisa. Dificuldades de aprendizagem de A a Z: Um guia completo para pais e educadores. Porto Alegre: Artmed, 2008.

TEIXEIRA, Josele; NUNES, Liliane. Avaliação inclusiva. Rio de Janeiro: Wak, 2010.

VYSGOTSKY, Lev Semenovitch. A formação social da mente. 3 ed. São Paulo: Fontes, 1988. 


\section{RESUMO}

Este artigo pretende mostrar a importância das adaptações do currículo, da avaliação, dos materiais didáticos e do papel do professor, diante dos alunos com deficiência intelectual - síndrome de down no ensino regular. Os objetivos aqui apresentados são favorecer ensino e aprendizagem através dos materiais e adaptações de acesso ao currículo e a avaliação. A metodologia utilizada nesta pesquisa são pesquisas bibliográficas. Conclui-se que por meio dos materiais adaptados todos os alunos com deficiência intelectual - síndrome de down são beneficiados, e torna possível uma prática pedagógica de forma igualitária e qualitativa garantindo uma educação para todos, priorizando cada um, independentemente de suas limitações. Os materiais adaptados, o currículo e avaliação otimizam a cooperação entre aluno e professor no processo de ensinoaprendizagem, valorizando a diversidade como agente de transformação de consciência social.

Palavras-chave: deficiência intelectual, síndrome de down, adaptações, currículo, avaliação.

\section{ADAPTATIONS IN THE INCLUSION PROCESS - DOWN SYNDROME IN THE OPTICS: CURRICULUM, EVALUATION AND DIDACTIC MATERIALS}

\section{ABSTRACT}

This article intends to show the importance of the adaptations of the curriculum, assessment, teaching materials and the role of the teacher, in front of the students with intellectual disability - Down syndrome in regular education. The objectives presented here are to favor teaching and learning through the materials and adaptations of access to the curriculum and the evaluation. The methodology used in this research are bibliographic research. It is concluded that through the adapted materials all students with intellectual disability - Down syndrome are benefited, and makes possible a pedagogical practice in an egalitarian and qualitative way guaranteeing an education for all, prioritizing each one, regardless of their limitations. Adapted materials, curriculum and assessment optimize student-teacher cooperation in the teaching-learning process, valuing diversity as an agent of transformation of social consciousness, enabling the exercise of citizenship in the construction of a more just society.

Keywords: intellectual disability, down syndrome, adaptations, curriculum, evaluation.

\section{ADAPTACIONES EN EL PROCESO DE INCLUSIÓN - SÍNDROME DE DOWN EN LA ÓSTICA: CURRICULUM, EVALUACIÓN Y MATERIAL DIDÁCTICOS}

\section{RESUMEN}

Este artículo pretende mostrar la importancia de las adaptaciones del currículo, de la evaluación, de los materiales didácticos y del papel del profesor, ante los alumnos con discapacidad intelectual - síndrome de down en la enseñanza regular. Los objetivos aquí presentados son favorecer la enseñanza y el aprendizaje a través de los materiales y adaptaciones de acceso al currículo y la evaluación. La metodología utilizada en esta investigación son investigaciones bibliográficas. Se concluye que por medio de los materiales adaptados todos los alumnos con discapacidad intelectual - síndrome de down son beneficiados, y hace posible una práctica pedagógica de forma igualitaria y cualitativa garantizando una educación para todos, priorizando cada uno, independientemente de sus limitaciones. Los materiales adaptados, el currículo y la evaluación optimizan la cooperación entre alumno y profesor en el proceso de enseñanza-aprendizaje, valorizando la diversidad como agente de transformación de conciencia social.

Palabras clave: deficiencia intelectual, síndrome de down, adaptaciones, currículo, evaluación.

Submetido em 21 de dezembro de 2018 Aceito em 30 de julho de 2019 